\title{
A DESCOBERTA DO NOME: O PRÓPRIO NA INFÂNCIA E NA ESCOLA
}

\author{
Cláudia Aparecida de Oliveira leite \\ Faculdade Pitágoras, Divinópolis, Minas Gerais, Brasil
}

\begin{abstract}
Resumo: Este artigo problematiza a construção do nome próprio na infância, demarcando como eixo de investigação teórica, a perspectiva psicanalítica. Dessa maneira, consideramos a incidência da linguagem e o laço relacional como os operadores privilegiados na constituição subjetiva, na medida em que o bebê humano é inundado pela linguagem que o antecede e o rodeia. Nessa imersão, a criança herda um nome de um outro, e é convocada a responder por esse nome. Entretanto, a apropriação desse nome requer um movimento solidário que corresponde ao reconhecimento de um corpo próprio. Tais operadores se estabelecem pela marca de um initium subjetivo, passo inaugural para a constituição do sujeito. Ao considerar tais elementos, pretendemos estabelecer um diálogo com o campo da educação, pois a escola ocupa uma função mediadora no processo que autentica, para cada criança, a conquista de seu nome próprio.
\end{abstract}

Palavras-chave: Nome próprio. Infância. Psicanálise. Educação.

DIMENSÕES DA HERANÇA

Aquilo que herdaste de teus pais, conquista-o para fazê-lo teu. (GOETHE apud FREUD, 1913 [1912-13] 1969, p. 160)

A força que a palavra hereditariedade ganha em nossos dias está vinculada ao estatuto que ela encontrou no campo da biologia e, em especial, 
nos estudos da genética. Entretanto, não devemos nos esquecer que a dimensão de uma herança ultrapassa as condições objetivas ou localizáveis cientificamente. Herdam-se promessas, histórias, traços, nome. Nesse sentido, o nome que cada um possui é uma herança na medida em que foi escolhido e doado por outra pessoa. Esse fato denuncia a dimensão de prematuridade e de dependência que marcam vivamente a chegada da criança no mundo. $A$ criança, que ao nascer encontra uma trama de linguagem e afetos a esperála, sobreviverá pelo amparo que advém de outro semelhante. Nesse enredo torneado de palavras, o nome se instaura demarcando uma trama singular que arrebata o infans e o antecipa como sujeito.

Dessa maneira, dentre as palavras que a criança recebe, haverá uma que tem a função de nomeá-la. O que implica, como nos lembra Vorcaro (1997, p.72), que "esta posição de sujeito antecipado pelo agente materno aloca este ser ao nome próprio introduzido pela atividade linguageira que o fisga na estrutura da linguagem que antecede sua existência real". O estatuto da nomeação inscreve o pequeno ser em uma linhagem, esboçando o contorno de sua história. Essa dimensão inaugural dá ao nomear o estatuto de ato, uma vez que inscreve um initium subjetivo.

A nomeação, oferecida pelo adulto que cuida da criança, marca de maneira radical a vivência da mesma. Nesses termos, Lacan, durante o Seminário IX - A identificação (1961-1962), destaca que só é possível apontar o sujeito na implicação do traço unário por um initium subjetivo, que só é estabelecido pela introdução primeira de um significante. Lacan (1961-62) aponta que o nome próprio é um significante puro, que vale por sua função distintiva demarcando um traço único, pois, para ele, "nomear é, primeiramente, algo que diz respeito a uma leitura do traço Um, designando a diferença absoluta". Nessa função significante que funda o initium subjetivo, encontramos, segundo Lacan, "o ponto de amarra de alguma coisa de onde o sujeito se constitui e que toca na função do nome". O nome próprio, tal como articulado por Lacan, está intimamente vinculado à problemática da identificação.

Após receber um nome, o sujeito tem que fazer um esforço para se apropriar desse som e das letras que servem para representá-lo. Dessa maneira, na apropriação do nome, o movimento para torná-lo próprio é solidário à constituição do sujeito, pois situa os meandros da identificação e se destaca como uma experiência fundante. Nesse intento, o nome próprio se enlaça ao corpo e ao mesmo tempo ultrapassa esse corpo, já que continua ressoando para além do corpo vivo. O nome próprio, portanto, transita pela 
cultura e marca o lugar de um ser humano na história. Esse enlaçamento tão complexo ocupa um lugar privilegiado na infância, pois corpo e nome são trançados na perspectiva constitutiva que contempla cada sujeito ainda antes do nascimento.

MOVIMENTO SOLIDÁRIO: CORPO PRÓPRIO-NOME PRÓPRIO

No enlaçamento do nome próprio ao corpo, há, na leitura desse traço único, algo que se movimenta pela apropriação. Nome e corpo precisam ser conquistados e apropriados - na dupla acepção do termo'. A conquista do corpo próprio revela os movimentos constitutivos que tem no estádio do espelho ${ }^{2}$ um instante lógico fundamental, pois nele a criança reconhece jubilosa a totalidade de sua imagem. Essa passagem requer a presença do semelhante, como nos lembra Cruglak (2001):

Que o sujeito possa aceder a seu próprio corpo não é algo natural. O corpo, o que chamamos corpo próprio, sofre um dispêndio de gozo pelo fato de que é tomado pelo significante precisamente para ser corpo. O que distingue 'essa presença de corpo animal do que logo nomeamos corpo próprio' é a inscrição de uma marca significante. Isso depende inteiramente do Outro não somente porque, como bem sabemos, o significante está no campo do Outro, senão porque é um 'pequeno gesto de amor' que esboça a marca. (CRUGLAK, 2001, p. 129).

O nome requer um trabalho por parte do sujeito para tornar-se próprio. Quando Lacan apresentou o seminário Problemas Cruciais para a Psicanálise (1964-65), durante a lição ministrada em 07 de abril de 1965³ , ele ressaltou a mirada que é preciso dar ao próprio no que concerne ao nome. Dessa maneira, ele assevera que a função essencial do nome é ser a palavra que nos mostra da maneira mais própria. O que o nome demarca é a conquista do próprio. Um nome próprio - marca distintiva - possui uma intimidade com o corpo de maneira tal, que podemos sustentar que o nome próprio é a condição para que haja corpo. ${ }^{4}$

Consideramos, portanto, que a constituição do sujeito requer um enlaçamento entre o organismo vivo, o corpo e o nome. Esse enlaçamento deve ser demarcado por um movimento solidário entre o organismo ancorado no registro do Real -, o corpo na perspectiva imaginária e o nome em sua dimensão simbólica. Real, simbólico e imaginário se estabelecem como os três registros da experiência humana, que Lacan trançou quando apresentou o nó borromeano 5 . 


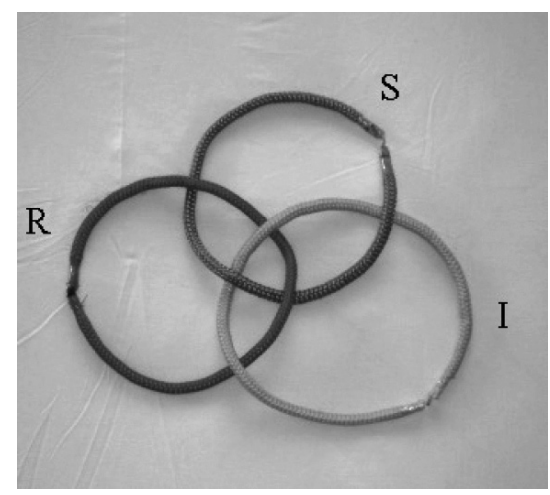

Figura 1 - Nó borromeu

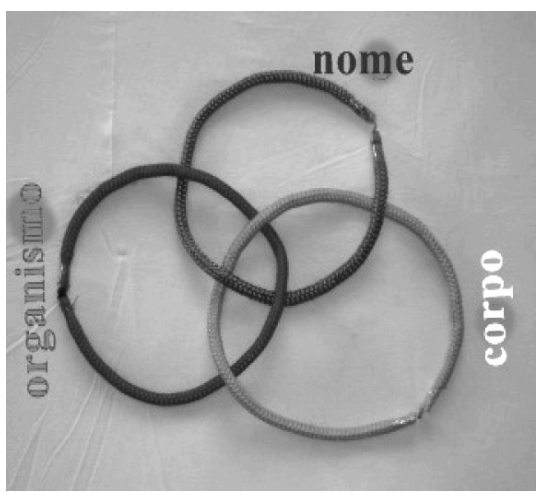

Figura 2 - Nó borromeu

organismo-nome-corpo

A trança borromeana constitutiva ${ }^{6}$ nos permite considerar os registros RSI (Real -Simbólico - Imaginário) pela perspectiva do organismonome-corpo. Essa formulação só é sustentável se considerarmos o initium, o traço unário, anterior ao sujeito em sua função inaugural. Corpo e nome são fundados no que o nome, ao fazer furo, esboça o corpo e a carne (organismo). Nesse traçado, o corpo se engancha ao nome. No mesmo lance, o nome ganha o estatuto de próprio ao mostrar um corpo da maneira mais própria. O nome faz furo no organismo, mas no mesmo lance se estabelece como sutura ao costurar o corpo. Esse é o movimento de trança subjetiva que enlaça nome-corpo-organismo.

A criança é convidada a dar conta do seu nome e do seu corpo desde muito pequena. No convívio familiar, o prenome (nome) é uma marca da distinção entre a criança e seus irmãos enquanto o sobrenome (marca de filiação) inclui o pequeno ser no grupo familiar. Ao ser encaminhada para a escola, a criança carrega seu nome e tem que responder por ele. Essa experiência de sustentar o próprio nome traz toda sorte de desdobramentos. Desde a advertência que determinados sobrenomes apresentam no seio social e no contexto escolar, até o desconforto que determinada nomeação promove, ou pela diferença sonora do nome ou pelo estranhamento oriundo do sentido previamente imposto. A escola, dessa maneira, pode ser entendida como o primeiro lugar social em que a criança vivencia o acontecimento do nome próprio fora do seio familiar. O que inclui os educadores numa função privilegiada na atenção que é dada ao nome. 
Não há nenhuma novidade em dizer que os educadores reconhecem o valor do nome próprio na vivência do sujeito e na construção identificatória da criança. É consenso entre os educadores e as instituições de educação infantil a utilização de projetos que destacam a importância do nome próprio. A história do nome e as formas de representação deste são trabalhadas criativamente dentro desses projetos, que incluem também o resgate da árvore genealógica da criança, sua filiação, linhagem, e sua inclusão no mundo. Tais iniciativas contribuem para que a família participe da construção de uma gesta, resgatando o sentido do nome e destacando as "onomatopeias de esperança", incluídas no ato de nomeação de cada criança.

Além desses projetos que contemplam a história do nome da criança, a prática da alfabetização pelo nome tornou-se frequente nas atividades de escrita/ensino desde a educação infantil. Duran (1994) nos lembra que esse fato revela a influência direta dos trabalhos de Emília Ferreiro e Teberosky na cena educativa. As autoras propuseram conhecer e investigar como as crianças lêem e escrevem antes da aprendizagem formal da língua. Diante dessa meta investigativa, elas destacam o domínio evolutivo da escrita e, segundo Duran (1994), "as pesquisas sobre a psicogênese da língua escrita representam um marco, podendo-se mesmo falarem de alfabetização antes e depois de Emilia Ferreiro". A construção da escrita percorrendo as letras dos nomes se situa de forma privilegiada no domínio evolutivo da leitura/escrita.

Aprender a ler e a escrever, se apropriando das letras do nome, é uma prática pedagógica que também está em consonância com a proposta de Paulo Freire, para quem a leitura do mundo precede sempre a leitura da palavra, ou seja,

a leitura da palavra, fazendo-se também em busca da compreensão do texto e, portanto, dos objetos nele referidos, nos remete agora à leitura anterior do mundo. O que me parece fundamental deixar claro é que a leitura do mundo que é feita a partir da experiência sensorial não basta. Mas, por outro lado, não pode ser desprezada como inferior pela leitura feita a partir do mundo abstrato dos conceitos que vai da generalização ao tangível. (FREIRE, 2001)

Saber seu nome e o modo de inserção desse nome em uma linhagem, são pontos fundamentais para a experiência da leitura/escrita, segundo a perspectiva dos autores supracitados. O nome próprio torna-se "palavra-chave" na escola, transitando, inclusive, nos pertences das crianças (mochila, copo, 
caderno, merenda etc. $)^{7}$. Na função de "palavra-chave" o trabalho com o nome no contexto escolar possibilita os movimentos de apropriação e construção da singularidade para a criança. Se o nome é um elemento marcante na constituição do sujeito, e se a escola é, frequentemente, o primeiro lugar de trânsito social do nome próprio da criança, destacamos o quão rico pode ser para o processo educativo se o trabalho com o nome próprio for realizado para além dos propósitos da alfabetização ou da distinção.

Queremos retomar uma experiência que contribui para nossa reflexão. Há alguns anos, no Brasil, algumas pré-escolas (jardins de infância) solicitavam que o nome próprio da criança fosse bordado em letras de forma na parte superior do uniforme (jardineira). Era um bordado manual, artesanal, feito para cada um, para cada nome. Essa prática foi abolida, mas os adultos que passaram por essa experiência de carregar o nome próprio no peito, falam dessa vivência ainda hoje, nos relatos clínicos. Certamente, os relatos que mais reacendem as discussões sobre o tema são daqueles sujeitos que não gostavam de seus nomes. Eles relatam a vergonha que sentiam ao ver "aquelas letras estampadas" que serviam para convocá-los. Infelizmente, naquele tempo, a criança não encontrava facilmente espaço para dizer da vergonha ou do mal-estar que sentiam em desfilar diariamente com seu nome próprio estampado para ser lido pelo outro. Os relatos dos adultos nos mostram claramente as consequências que a circulação do nome pode trazer à constituição da subjetividade.

O compromisso educacional reconhece gradativamente a dimensão subjetiva que está em jogo na apropriação de um conhecimento e na implantação deste como saber. Reconhecer a dimensão subjetiva permite que a criança, além de aprender o nome que recebeu - objetivo fundamental nas estratégias de alfabetização e nos projetos sócio-pedagógicos -, conheça o nome que tem ${ }^{8}$. A escola, nos próprios projetos que ela constrói, pode permitir ser um espaço de "memorial do ato de nomeação". Nesse sentido, podemos demarcar que o verdadeiro sentido da descoberta do nome é permitir o passo que advém do saber fazer o nome (fundamental na experiência da escrita) para o saber-fazer com o nome, isto é, torná-lo próprio. 


\section{DISCOVERING NAMES: ONE'S OWN IN CHILDHOOD AND IN SCHOOL}

ABSTRACT: This paper raises the issue of constructing one's own name in childhood by adopting the psychoanalytic perspective as its theoretical investigative approach. Thus, we consider the occurrence of language and the relational tie as privileged operators in subjective constitution, as the human infant is overwhelmed by the language that precedes and surrounds it. In this immersion, the child inherits a name from another and is called on to respond by that name. However, the appropriation of this name requires a solidary movement that corresponds to the recognition of one's own body. Such operators are established by the mark of a subjective initium, which is the first step for the constitution of the subject. By considering these factors, we intend to establish a dialogue with the field of education, since the school plays a mediating role in this process, which for each child, authenticates the acquisition of their own name.

KEYWORDs: Own name. Childhood. Psychoanalysis. Education.

\section{LA DESCUBIERTA DEL NOMBRE: EL PROPIO EN LA NIÑEZ Y EN LA ESCUELA}

RESUMEN: Este artículo problematiza la construcción del nombre propio en la niñez, demarcando, como eje de la investigación teórica, la perspectiva psicoanalítica. De esta forma, consideramos la incidencia del lenguaje y el lazo relacional con los operadores privilegiados en la constitución subjetiva, en la medida que el bebé humano es inundado por el lenguaje que le antecede y le rodea. En esta inmersión, el niño hereda un nombre por parte de otro y es llamado a responder por ese nombre. Sin embargo, la apropiación de ese nombre demanda un movimiento solidario que corresponde al reconocimiento de un cuerpo propio. Estos operadores se establecen por la marca de un initium subjetivo, pasaje inaugural hacia la constitución del sujeto. Al considerar tales elementos, pretendemos establecer un diálogo con el campo de la educación, ya que la escuela ocupa una función mediadora en el proceso que autentica, a cada niño, la conquista de su nombre propio.

Palabras Claves: Nombre propio. Niñez. Psicoanálisis. Educación.

\section{NOTAS}

1) Apropriado pode ser lido aqui na sua dupla acepção: a) como algo de que se apropriou; e b) algo próprio para determinado uso ou fim; adequado, conveniente.

2) No texto de 1949, Lacan situa a compreensão do Estádio do Espelho na construção da identificação, e afirma: "O estádio do espelho é um drama cujo alcance interno 
precipita da insuficiência para a antecipação - e que fabrica para o sujeito, apanhado no engodo da identificação espacial, as fantasias que se sucedem desde a imagem despedaçada do corpo até uma forma de sua totalidade que chamaremos ortopédica...." (LACAN, 1998 [1949], p. 100).

3) Seminário XII - Problemas cruciais para a psicanálise (1964-65) [inédito].

4) Cf. LEITE (2008).

5) O nó borromeano é enlaçado de tal forma, que cada aro mantém uma relação idêntica com seus vizinhos. $O$ fato de soltar um dos aros faz com que os outros também se soltem; essa é a característica fundamental do nó borromeu.

6) Sobre esse tema, conferir Vorcaro (1997).

7) Partilho o relato de uma avó que, ao questionar a netinha de três anos sobre como ela diferenciava sua maleta de merenda, uma vez que ela não sabia ler os nomes, a netinha respondeu: "pra saber, vovó, eu só preciso saber o meu (nome)".

8) Referência a José Saramago, que demarca: “Conheces o nome que te deram, não conheces o nome que tens". (Livro das Evidências).

\section{REFERÊNCIAS}

CRUGLAK, C. Clínica da Identificação. Rio de Janeiro: Companhia de Freud, 2001.

DURAN, M. C. G. Alfabetização: teoria e prática. In: Série Ideias, n. 20. São Paulo: FDE, 1994. p. 105-113.

FREIRE, P. Carta de Paulo Freire aos professores. Estudos Avançados, São Paulo, v. 15, n. 42, ago. 2001.

FREUD, S. Totem e tabu (1912-13). In: Obras Completas. Rio de Janeiro: Imago Editora, 1969.

LACAN, J. O Seminário, 9 - A identificação (1961-1962). Inédito. . O Seminário, 12 - Problemas cruciais para a psicanálise (1964-1965). Inédito. . O estádio do espelho como formador da função do eu. In: . Escritos. Rio de Janeiro: Jorge Zahar Editor, 1998.

LEITE, C. A. O. Quando o Corpo pede um Nome: a título provisório. Tese (Doutorado em Linguística) - Instituto de estudos da Linguagem da Universidade Estadual de Campinas (UNICAMP), Campinas-SP, 2008.

VORCARO, A. A Criança na Clínica Psicanalítica. Rio de Janeiro: Companhia de Freud, 1997. 
Cláudia Aparecida de Oliveira Leite é graduada em Psicologia pela Universidade Federal de Minas Gerais (1996), mestre (2004) e doutora em Linguística (2008) pela Universidade Estadual de Campinas. É pesquisadora associada do Centro de Pesquisa Outrarte (IEL/ Unicamp), membro do Projeto \$EMA\$OMa (IEL/UNICAMP). Pesquisadora do Grupo de Pesquisa Psicanálise, Subjetividade e Cultura (UFRB). Pós-doutorado em Psicologia Psicanalítica do Sujeito (Laboratoire Clinique Psychopatologique et Interculturelle/Université Toulouse II - Mirail). Membro fundadora do Parlêtre: Psicanálise, Pesquisa e Transmissão (2005 - Divinópolis/MG). Tem experiência na área de Psicologia e Psicanálise, atuando principalmente nos seguintes temas: Psicanálise; nome próprio; clínica psicanalítica; linguagem; escrita; sujeito.

E-mail: caoleite@yahoo.com.br 